This file is to be used only for a purpose specified by Palgrave Macmillan, such as checking proofs, preparing an index, reviewing, endorsing or planning coursework/other institutional needs. You may store and print the file and share it with others helping you with the specified purpose, but under no circumstances may the file be distributed or otherwise made accessible to any other third parties without the express prior permission of Palgrave Macmillan. Please contact rights@palgrave.com if you have any queries regarding use of the file.

\title{
Proof
}

\section{1 \\ Building Trust at the Beginning of a New Leadership Role: The Role of Learning and Collaboration}

Paul Atkins

\section{Entering a new public manager's role}

The nature of public sector management and leadership is changing. To address whole-of-government and whole-of-society challenges, public sector organizations are exploring more collaborative forms of leadership (Alford and Hughes, 2008; Getha-Taylor, 2008). Leadership, particularly at senior levels, is becoming more about influencing across boundaries, taking broader and more multiple perspectives and about recognizing and integrating complexity (Hooijberg and Schneider, 2001; Karp and Helgø, 2008). And in public organizations in particular, there are increasing demands for transparency and high ethical standards from leaders.

This chapter explores how middle to senior managers in the public sector might begin a new leadership role in such a way that they a) recognize and learn about the complexity of the challenges they face and $b$ ) build trusting collaborative relationships with staff and stakeholders from the beginning. In complex, multi-stakeholder environments such as those that face most public sector managers, learning and building trust are critical for effectiveness. Subašić and Reynolds (this volume) focus on ways in which creating clear differentiation between identity groups may aid the new leader in developing their power base. In contrast, covering managerial rather than political successions, this chapter emphasizes processes of integration rather than differentiation, focusing on developing trust and learning. It seeks to develop an approach to succession that is less reactive and more responsive than that usually adopted by default in most complex organizations, public as well as private.

The period of succession into a new leadership role is critical for establishing trust and credibility in the role of the leader. Just as the new leader can see with fresh eyes, they also receive heightened attention from their managers, peers and subordinates. It is a rare opportunity to learn, both for the 
leader and for their colleagues and the organization as a whole. Used well, the 'honeymoon' period can be a uniquely productive time for examining old assumptions, creating new alliances and using heightened scrutiny to model desired changes in organizational culture (Appelbaum and Valero, 2007).

But there are also substantial risks during the time of entry into a new leadership role. This chapter is focused on one of those risks: The tendency for new leaders under stress to process information privately rather than collaboratively. The chapter begins with a review of the situational, cognitive and emotional demands upon a new leader in the middle to senior ranks of the public service. It then describes how one natural consequence of these demands is a tendency for new leaders to process information privately. After that, the risks and benefits of private and collaborative processing are explored with reference to two key criteria for a successful transition: learning and building trust. A practical, planned approach to commencing a new role is then presented and evaluated in the context of the public service.

\section{The demands of a new leadership role}

The newly appointed leader in the public service faces significant situational, cognitive and emotional demands. The situation often requires the new leader solves immediate and pressing operational problems quickly. For example, one of my coaching clients was told during an interview for a new middle management role that she was the 'silver bullet' and that she 'had been brought in to fix all that had gone before and to make a dysfunctional area functional'. New leaders are naturally proud of their abilities and determined to make a positive difference so it is natural to narrow their attention to providing immediate solutions.

In many public service agencies, this tendency is further supported by a culture that rewards 'heroic' leaders who offer solutions instead of questions and problem statements. Reward structures and probationary periods are such that the most salient task for a new leader is to impress upwards rather than build relationships down and out. For example, in the Australian Public Service framework, the competency 'Achieves Results' is sometimes seen as the only one that really matters (Australian Public Service Commission, 2004). Furthermore, in situations with rapid turnover of job roles, there seems little point fostering long-term relationships with staff and stakeholders when relationships are likely to change within a relatively short period.

In short, the context for a new leader in the public service often involves too little time, too much to learn, pressing problems created by others but usually with little agreement as to the nature or extent of the problems; uncertainty regarding who to trust; heightened scrutiny from managers, 


\section{Proof}

peers and subordinates; limited scope to make decisions independently with numerous, complex connecting elements and strong demands to 'hit the ground running'.

These contextual factors obviously place significant emotional demands on the new leader. Even if the leader is one who thrives under pressure, significant elements of this context are likely to be perceived as threatening or potentially threatening. In situations of perceived threat, we appear to be 'programmed' to focus attention and act rapidly and automatically (Fredrickson, 2000). This is the so-called fight-flight response, a sophisticated combination of cognitive, emotional and somatic reactions leading to rapid and automatic action to reduce threat (Sapolsky, 1995). From an evolutionary perspective, narrowed attention and rapid reactions are necessary to deal with threatening situations. However this pattern of response may be sub-optimal in modern complex environments where situational awareness, informed problem framing and stakeholder relationships are crucial.

Finally new leaders often face significant cognitive demands. In complex environments with multiple elements and non-linear relationships, human beings appear to be biased towards rapidly seeking to trial possible solutions rather than spending time clarifying and defining problems and goals (Dörner, 1996). One reason why this occurs is that we wish to protect our sense of competence, and exposing ourselves to the uncertainty and ambiguity of complex issues and relationships feels deeply uncomfortable. Furthermore, public servants are not rewarded for professing ignorance and so are likely to rapidly, and even unconsciously, frame issues in such a way that they have solutions ready to hand. Dörner (1996) refers to this automatic tendency to see a problem in terms of known solutions as 'methodism'.

The following case history illustrates this tendency: John was the new Branch Head of the HR department for a major Australian government agency. He came to the position having been acclaimed for a highly successful change initiative in a smaller agency where he dramatically increased the amount and scope of training that staff received. After an initial 'meet and greet' with a variety of stakeholders, he noticed clear capability deficits and he formed the opinion that what was needed was an increase in the amount and variety of training. This opinion was only reinforced following his discussions with the training unit.

John knew he was well placed to use training as a major lever for change. His connections to a variety of training companies meant he knew the industry and he was himself a fantastic trainer. In the first days of his tenure, he called his staff together and clearly articulated his vision for what could be accomplished by improving the skills and capabilities of the entire agency. Although there were some murmurings about all the other work that needed to be done, in general his staff were enthusiastic about the possibilities for new challenges, getting beyond their procedural work and for engaging 
194 Building Trust at the Beginning of a New Leadership Role

more with the rest of the agency. In those first days, John quickly established his authority as an energetic, clear-headed and hard-working leader offering a new and exciting direction and identity for the role of HR in the agency.

Unfortunately within six months, the gloss had worn off. Senior management had received numerous complaints regarding poor handling of basic systems of leave, pay and recruitment and one particularly prominent staff dispute remained unresolved. John was reassigned to a special project and a new leader was appointed who, in turn, wound back many of the training activities of the HR department and established a 'back-to-basics' philosophy. Before long the agency was in much the same position as it was before John commenced his role.

So what went wrong? I chose this story because, in some ways at least, John did all the 'right' things as a new leader: consulting with key stakeholders, identifying a clear and compelling direction for change, and implementing his vision with energy, expertise and enthusiasm. Below, I argue that John's response to the demands of a new leadership role, while quite typical and natural given our evolutionary programming, is inadequate for the needs of the modern public service, demonstrating how what I call private processing of information can impair both individual and organizational learning.

\section{A common new leader syndrome: Private processing of information}

With hindsight it seems obvious John was too strongly influenced by his previous experience and did not adapt appropriately to the new situation. New leaders feel great pressure to provide solutions to pressing problems so that they demonstrate their ability and establish their authority. John failed to assist his agency largely because of the way that he paid attention in the early days of his new leadership: selectively noticing aspects of his experience that fitted with solutions he had confidence in offering; discounting experiences that did not support his identity as a progressive, knowledgeable leader; failing to engage in a sufficiently collaborative way to expose and grapple with the inevitable tensions and resource allocation issues afforded by a major change programme; and failing to develop his own team - leaving them vulnerable to yet another leader with the 'silver bullet' for success. In short, John focused and acted on his own private reasoning and activity without building a collaborative environment to test his agenda and understanding publicly.

Private processing of information is a form of defensive behaviour that negatively impacts upon individual and organizational learning. Emphasizing the importance of error-detection and correction for organizational learning, Argyris and Schon (1978) distinguished between Model 1 behaviours, which involve conflict avoidance and self-protection; and Model 2 behaviours that 


\section{Proof}

involve relational transparency, public reflection and double-loop learning. People engage in model 1 behaviours, such as concealing their agenda and private information processing because they are fearful that being open about their aims, uncertainties, and information processing may expose them to conflict, questioning or ridicule. Of course, not all new leaders face the same demands or react the same way, but the situation and responses described above are common enough to make it worthwhile to explore the consequences and what might be done about it.

So far I have argued that the social environment for a new leader in the public service often makes substantial cognitive and emotional demands upon new leaders. These demands include deeply embedded tacit assumptions that problems and solutions exist somehow independently of the perspectives brought to them, and that the role of the new leader is to fix those problems as quickly as possible. These assumptions and social demands, combined with natural, evolved patterns of psychological reaction; push the leader towards narrowing their attention and relying heavily upon their own resources and past experience in order to prove themselves by fixing things. The result is that new leaders tend to conduct private reasoning regarding:

- The data: in the form of selective noticing and attending;

- The nature of the problem: in the form of attributing causes and inferring the nature of the problem; and

- The potential solutions. In the form of creating or replaying previously successful action plans.

The first two of these, data selection and problem framing are also particularly likely to be conducted 'on-the-fly', reactively and automatically. To the extent that these processes occur outside of rational awareness they are prey to systematic distortions such as the availability bias (Tversky and Kahneman, 1974), confirmation bias (Gilbert, 1991) and defensive routines to avoid uncertainty, conflict and perceptions of incompetence (Dörner, 1996).

The demands outlined above can be seen as a set of tacit short-term criteria for a successful succession. But if we broaden our focus to consider how a new leader might make progress on complex organizational challenges in the longer term, a different set of criteria come into focus. These long-term criteria are relevant even in the first days of succession because patterns of interaction tend to persist and the first days of a new role are the best opportunity the leader will get for learning. Figure 11.1 represents possible criteria for a successful succession, from the perspective of the leader, in terms of an inherent tension between short- and long-term interests.

The urgency of the short-term demands means that they dominate the agenda of a new leader unless (s)he engages in a conscious and deliberate 
Building Trust at the Beginning of a New Leadership Role

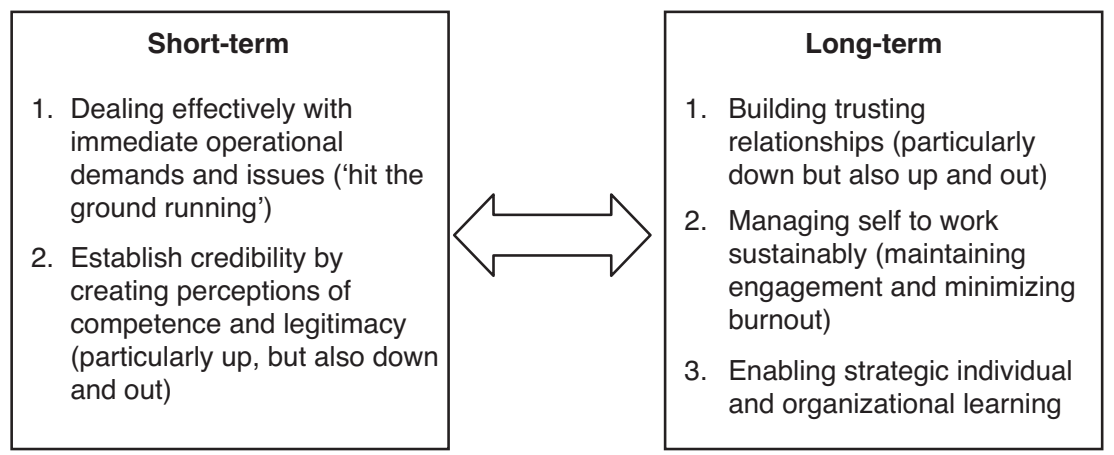

Figure 11.1 Short-term demands versus long-term interests. 'Up' refers to one's managers, 'down' refers to one's team while 'out' refers to peers and stakeholders

strategy for entering the role. I explore such a deliberate strategy towards the end of this chapter. But in the following section I aim to make the case that leaders can and should consider the long-term criteria even in the face of the short-term demands of succession.

\section{An alternative: Building trust through authentic leadership}

Trust is essential for long-term team performance and successful stakeholder engagement. When followers trust their leaders, they perform better on jobrelevant tasks, engage in more organizational citizenship behaviours, experience greater job satisfaction, display greater organizational commitment, and are less likely to wish to leave the organization (Dirks and Ferrin, 2002). Furthermore, team and organizational performance is improved (Burke et al., 2007) and followers are more likely to be satisfied with their leaders and perceive their leader to be effective (Gillespie and Mann, 2004).

So how is trust in a leader developed? There is now good empirical evidence on this question, and the answer is complex. In a multi-level review, Burke et al. (2007) pointed to a range of antecedents and moderators of trust in leadership. Antecedents included a consultative leadership style, behavioural integrity (consistency of word and deed), leader ability, and benevolent behaviour; while moderators included leader reputation as well as trustor, team and organizational characteristics. Trust is developed through being capable, conveying legitimacy and purpose, doing what one says one will do and involving others in decisions.

Of these, most new leaders seem to tacitly focus upon demonstrating their ability and bolstering their reputation in order to build trust. In an environment where they do not know who to trust and how much, rather than depend upon others new leaders seek modes of action that rely first and foremost upon their own capabilities. One way they can do this is to 


\section{Proof}

dive into solving pressing and complex problems. Their capability is thus demonstrated through immediate achievement. But this is a high-risk strategy, which often sees the leader working on the wrong issues or ignoring valuable contributions from others in the process. In that case, efforts at unilateral problem solving result in trust evaporating rather than being built. In a connected world, we need more sustainable and reliable ways to establish leadership authority and trust.

One factor that appears to be critical in doing so is a consultative leadership style. Involving followers in participative or at least consultative decisionmaking generates perceptions of organizational justice and trust in the leader (Dirks and Ferrin, 2002). Indeed, Gillespie and Mann (2004) found that consultation with team members was one of three key factors (along with communicating a vision and establishing shared values) that accounted for 67 per cent of the variance in team members' trust towards their leaders. Consultative leadership enhances perceptions of autonomy which, in turn, enhances motivation and engagement in followers (Stone et al., 2009). Furthermore, consultation helps develop a clear sense of shared purpose and empowers followers to realize that purpose (Burke et al., 2007). More broadly, the notion of relational transparency includes but extends the consultative leadership style. According to Mazutis and Slawinski (2008: 445) relational transparency:

[E]ncompasses all of the earlier capabilities in the act of open and truthful self-disclosure ... In addition to being self-aware, balanced and congruent in one's goals, motives, values, identities and emotions, authentic leaders are also transparent in revealing these expressions to their followers (Hughes, 2005). Disclosing one's true self to one's followers builds trust and intimacy, fostering teamwork and cooperation (Gardner et al., 2005) and feelings of stability and predictability (Chan et al., 2005). Furthermore, relational transparency requires the willingness to hold oneself open for inspection and feedback, thereby also being an essential component in the learning process (Popper and Lipshitz, 2000).

In other words, relational transparency involves risking vulnerability by revealing one's own mental and emotional processing for public scrutiny.

The consistency between the leader's word and deed, referred to as behavioural integrity, also appears to be critical for trusting a leader and may, in turn, lead to enhanced performance, satisfaction and organizational citizenship (Simons, 2002). Palanski and Yammarino (2009) used evidence from studies of transformational (Bass and Steidlmeier, 1999), authentic (Avolio and Gardner, 2005) and spiritual (Fry, 2003) leadership, which all feature behavioural integrity, to argue that behavioural integrity should positively affect at least the social aspects of leader performance (e.g. consulting stakeholders, managing conflict, giving feedback). 
Behavioural integrity builds trust because followers can more confidently predict the leader's behaviour. But such confidence arises from a pattern of consistent behaviour over time. To be consistent in the face of a changing and demanding environment, the leader needs to be able to effectively selfregulate (Atkins, 2008). Self-regulatory capability is what allows us to predict our behaviour and to regulate our internal and external state in order to achieve valued ends. So to act with integrity in a changing complex environment, leaders require self-awareness, as manifested by an ongoing, dynamic appreciation of their own sense-making in context. In other words, leaders need to be able to take a perspective on their own values, emotions, identity and characteristic behavioural reactions in relationship to their experience of the world (Kegan, 1994).

One recent approach to leadership development that has brought together these elements of relational transparency, behavioural integrity and self-awareness is that of authentic leadership (Avolio and Gardner, 2005). Gardner et al. (2005) define authenticity as 'both owning one's personal experiences (values, thoughts, emotions and beliefs) and acting in accordance with one's true self (expressing what you really think and believe and behaving accordingly)'. More specifically, authentic leadership has been characterized in terms of four factors: self-awareness, authentic behaviour, balanced processing and relational transparency. Self-awareness includes not just awareness of the content of one's experience but also of the epistemological process of framing and constructing that experience. Authentic behaviour is similar to behavioural integrity in that it involves a consistency of word and deed. But it also includes the idea of being true to oneself. According to Kernis (2003: 14) 'behaving authentically means acting in accord with one's values, preferences, and needs as opposed to acting merely to please others or to attain rewards or avoid punishments'. In this sense, authentic behaviour reflects intrinsic motivation and self-determination (Deci and Ryan, 1985, 2008).

Balanced processing refers to being able to rationally process one's own and others' perspectives. It is about being open to self-relevant information without ego-defence. Authentic people 'are able to more objectively evaluate and accept both positive and negative aspects, attributes and qualities of themselves [and others], including skill deficiencies, suboptimal performance, and negative emotions' (Gardner et al., 2005: 356). This nondefensive and open awareness takes time to develop but it is central to effective dialogue and collaboration. Indeed, there is increasing evidence that this form of awareness, often referred to as mindfulness, is predictive of a wide range of positive health and performance outcomes (Brown et al., 2007).

Recently a measure of authentic leadership has allowed researchers to start exploring the impacts of this specific constellation of leader activities. Walumbwa et al. (2008: 111) found that their measure 'accounted for 


\section{Proof}

variance in a diverse set of frequently researched work outcomes beyond that explained by ethical and transformational leadership dimensions. Specifically, authentic leadership was shown to account for additional unique variance in OCB [organizational citizenship behaviours], organizational commitment, and satisfaction with supervisor. Thus, evidence was obtained of the value added by considering the effects of authentic leadership on commonly researched organizational variables beyond existing measures of related leadership constructs'. In addition, 'follower perceptions of the leaders' authentic leadership were positively related to individual follower job satisfaction and rated job performance, controlling for the effect of organization climate' (Walumbwa et al., 2008: 117). Authentic leadership appears to positively impact performance, job satisfaction as well as leader and follower wellbeing (see Avolio et al., 2009 for a review). Furthermore, trust in leadership appears to at least partially mediate the relationship between authentic leadership and performance (Clapp-Smith et al., 2009).

In summary, in this section I have reviewed evidence regarding the importance of trust in achieving positive work outcomes and discussed a form of leadership that appears to contribute to trust and performance. In terms of the demands of succession, I am suggesting that a leader might not only attend to the immediate demands, but could also consider what types of relationships they wish to develop in order to be most effective in the longer term. A leader who begins with private processing of information and unilateral action may rapidly resolve initial crises but the long-run impact may include undermining trust or, at the very least, disempowering followers to contribute at their best. Expectations, both positive and negative, become entrained such that early impressions influence later interpretations of leader actions.

Clearly trust and open communication facilitate organizational and individual learning. It is extremely easy for a person in authority to become isolated from the true opinions and perspectives of their followers and peers. But behaving in this collaborative way is by no means easy. Leaders often need to learn new ways of seeing their role and value, as well as more effective ways to express and regulate emotions. In the next section, I describe in detail one potential way in which a structured approach might be used to deliberately support a more collaborative and open form of engagement with staff.

\section{Enabling strategic individual and organizational learning: A structured approach to collaborative enquiry for the new leader}

In response to the challenges of a new leadership role Jentz (2008) proposed a process called 'EntryPlan' to strategically orient new leaders to their environment and establish credibility and trust up, down and outwards. The EntryPlan approach was designed to encourage new leaders to select 
data and define problems more consciously and publicly. In this section I briefly describe this approach and evaluate it in the light of the research described earlier. An EntryPlan comprises four stages: a) designing and public testing, b) gathering data, c) conducting joint sense-making, and d) collaborative action planning. Each of these stages is described in brief below and in detail by Jentz (2008). Importantly, this work does not occur instead of working on immediate and pressing problems, rather it is expected that these steps will be conducted as one project among others that need to be accomplished in the early days of a new leader's role.

Many new public leaders are, at least initially, primarily concerned with impressing those who appointed them. In my experience, it is important that the EntryPlan approach is endorsed by one's managers. The process appears to be most effective if the new leader sets expectations early that they are going to engage in a structured succession process that is designed to foster trust and learning. This process could start with the interview for the position, where having an EntryPlan is likely to be seen as a strong indicator of strategic thinking and commitment to the position.

\section{Stage 1: Design and test the EntryPlan}

Key decisions at this stage are: a) what is the purpose of the EntryPlan, b) who to talk to, and c) what questions to ask. The design can be conducted individually, with a manager or coach depending on the leader characteristics and the extent and nature of the demands of the leadership role.

\section{Designing the plan: What is the purpose of the EntryPlan?}

Two common reasons for engaging in this process are to orient to the strategic environment and to build relationships within one's own team. All leaders both set an agenda and respond to others' agendas. Leadership is a relationship between productive and receptive forces. But at senior levels, setting the agenda and deciding on strategic directions becomes a dominant responsibility over and above line management and operational tasks (Australian Public Service Commission, 2004). In the words of one Executive Director reflecting on his transition from being a Branch Head: '[the focus on task expertise and execution] dissipates and the expertise becomes more about stakeholder relationships and inter-governmental stuff and building that overall strategic knowledge into the organization'.

\section{Designing the plan: Who needs to be included in what steps of the process?}

At the more junior levels, leaders may focus on establishing relations with their direct reports during transition into the role. As the role becomes more senior, it is possible that the emphasis will shift from direct reports to strategic external stakeholders. This depends on what the leader hopes to 


\section{Proof}

achieve. Who do they most need to establish trust and credibility with? Who has the most critical perspectives for them to complete their work effectively? Stakeholders can be selected depending on their interest or power in the tasks relevant to the leader's role. While a first draft might be completed by the leader themselves, it is likely that the plan will go through a number of iterations including consultation with more senior leaders to determine key stakeholder relationships.

\section{Designing the plan: What questions to ask?}

The scope and focus of the plan will be determined by its purpose. Questions might focus on areas such as: a) issues and principles that matter most to the interviewee, b) what the interviewee might know that could help the leader succeed (or avoid failure), c) current issues facing the interviewee's organization/unit and what is on the horizon and d) how the different areas might effectively work together.

\section{Testing the plan}

Finally, in the spirit of collaborative reasoning, Jentz (2008) argues that the plan itself should be made public to others such as the leader's manager, their team or other key stakeholders who might be able to make useful contributions to its structure.

\section{Stage 2: Gathering the data through dialogue}

Within the EntryPlan process, initial data is usually gathered in structured and purposeful individual interviews with key stakeholders. This is quite different way to the usual 'meet-and-greet' sessions common within the public service which often do not have an explicit agenda beyond 'getting to know you' and are fairly unhelpful. Even where they do have an explicit agenda, they are rarely cast in such a way as to focus upon the different perspectives brought to the issues. Within the EntryPlan approach, data gathering has the qualities of dialogue rather than discussion:

a) Wherever possible, the agenda is open. Purposes are explicitly stated and checked with the other. (e.g. 'I would like to use this meeting to ... better understand your perspective on key challenges and strategic imperatives; ... to let you know how I am thinking about my role; ... to explore more effective ways for our groups to work together ... How is that for you?').

b) Conversation is conducted in such a way that, as much as possible:

i. The data (what actually happened or is happening) are kept separate from interpretations of those data (e.g. 'In the past our departments have often not shared information' is a much more useable framing of an issue than 'in the past our departments have concealed information from one another.' The latter infers negative intent that 
202 Building Trust at the Beginning of a New Leadership Role

reduces possibility of other interpretations and usually gets in the way of building relationships.)

ii. Interpretations are recognized as subjective rather than objective truths.

iii. The interviewer's interpretation of the interviewee's comments is made open for testing and further elaboration (e.g. 'So it sounds to me as though the biggest issue you are noticing here is $\mathrm{X}$, and you want $Y$, have I got that right?')

So in the EntryPlan approach, interviews have an explicitly stated purpose and are conducted using reflective listening skills closer to dialogue than simple discussion. Conversations that proceed along the lines of: 'What do you think?' and then 'That's interesting, here is what I think' do not typically reveal private assumptions and automatic processing.

\section{Stage 3: Collaborative sense-making}

The last two stages of the EntryPlan approach are making sense of the data and prioritizing actions. In some situations, the new leader may plan to simply conduct the data gathering publicly and then process that information privately or with selected colleagues. However, this is a lost opportunity to use the transition into a new role to demonstrate relational transparency and bring stakeholders together in a new and productive way. A middle manager who has focused their plan on conversations with direct reports could, for example, generate significant engagement, learning and trust by conducting sense-making and planning meetings with their team.

Collaborative sense-making involves the leader presenting back the sense they have made of the data gathered in stage 2 for further comment, integration and elaboration. This allows the leader to validate their understanding and acknowledge inputs from others. In my experience, collaborative sense-making works best if the leader is as transparent as possible and able to separate 'facts' from interpretations. It is at this point that the defensive behaviours mentioned above are most likely to occur. For leaders unaccustomed to genuine dialogue, this stage can feel extremely uncomfortable as what previously looked simple in their own minds become a complex web of potentially competing perspectives. To engage fully with that complexity seems to require all the self-regulatory skills discussed earlier. However, exposing this complexity can both inform the leader and make it clear to other stakeholders what constraints the leader is under.

\section{Stage 4: Collaborative Action Planning}

While the EntryPlan approach is specifically designed to encourage active and more deliberate 'sense-making', in order to make an impact there needs to be a translation into an action plan. In many public sector agencies, it seems that developing a prioritized action plan is the sole preserve 


\section{Proof}

of the leader (after all, what are they paid for?). But again, even if actionplanning is not done in a group, it can be conducted more collaboratively by, for example, developing a draft plan which is circulated for comment and input and may be integrated with a wider strategic plan.

So, in summary, while it is possible to conduct only the first two stages, conducting all four publicly and collaboratively could potentially generate value by a) improving the quality of information used by the leaders to make decisions, b) improving the quality of problem definition, c) increasing trust in the leader, d) setting expectations that others can and should contribute to solutions, e) increasing the ability of stakeholders to perceive complexity and develop experience and skills in working with others to figure out what to do in the interest of improving the organization, f) increasing shared understanding of current practice and what needs to change, and g) creating increased engagement through shared perceptions of the issues and potential action plans (Jentz, personal communication).

The process proposed by Jentz (2008) is potentially a 'recipe' for increasing relational transparency and, consequently, trust and learning as described earlier. Of course, there is a considerable amount of skill involved in conducting this process effectively and these skills appear to be the same as those associated with authentic leadership as described previously. The very act of engaging in learning about and conducting this process is, therefore, a potentially potent form of leadership development in its own right.

\section{Possible objections and risks}

In this chapter I have suggested that key tasks of a new leader include developing trust and learning as well as getting started on immediate work. Studies of leader trust and authentic leadership suggest that a collaborative and transparent approach is likely to be helpful. The EntryPlan process proposed by Jentz (2008) provides a structure within which a suitably skilled or supported leader could possibly avoid the pitfalls of private information processing and embody collaboration in the early days of their leadership, thereby building trust and learning.

In my experience, the collaborative approach presented in this chapter is sometimes seen as a bit unrealistic for the busy lives of public servants. And indeed, the importance of sensitivity to the specific demands of the leader's role cannot be underestimated. Sometimes, for example, a new leader simply will not have the time or authorization to engage in anything like the process discussed above. On the other hand, any new approach is likely to feel uncomfortable, and in this case this problem is particularly acute because it asks leaders to make use of self-regulatory skills that can be difficult and uncomfortable to learn. However, given appropriate placement during interviews and managerial support, the EntryPlan can be framed as an initial project that is part of the work. This view only makes sense when 
the 'real work' of leadership is seen as more than just providing solutions in the short term. If framing the right issues and developing the trusting relationships necessary for effecting change are also valued, then activities like collaborative sense-making make sense. As a Branch Director noted to me: 'when you really need something from one of the other agencies, if you haven't got those relationships built up, you just can't get it'.

In some ways, the environment of the public service is becoming increasingly supportive of collaborative approaches to succession. The push for 'whole-of-government' collaboration within public service agencies provides an excellent context for considering collaborative succession as part of the real work of a public leader. It is expected that senior leaders build relationships across agencies and seek ways of seeing strategic issues from multiple perspectives. But often, the whole-of-government message is largely aspirational, and lacks an actionable plan for individual leaders. A collaborative approach to succession like that outlined above offers an unparalleled opportunity to integrate across organizational boundaries.

Some leaders express concern about their capacity to be open about their reasoning and the collaborative approach does indeed call for more transparency than most of us are used to. Transparency can also be damaging if applied inappropriately for the context. It is obviously easiest to be open in high-trust situations and sometimes it is necessary to conceal aspects of our reasoning in low-trust situations. However, most of us systematically conceal aspects of our reasoning even in neutral situations because of largely personal reasons such as fear of appearing incompetent or naïve, giving away power or offending people. This chapter has suggested that leaders are likely to have more success building trust and learning if they are able to collaborate openly even in the face of these negative emotions. The evidence sug-gests that the most admired leaders are those who are willing to expose their reasoning to scrutiny and act with integrity (Kouzes and Posner, 2006).

Unfortunately, the cultures of many public service agencies do not support open sharing of information. One public manager described her experience of trying to engage in more open information sharing within the tax office as follows: 'sharing knowledge was an anathema to the way they operated, knowledge is power, so [sharing knowledge] was a threat'. Another expressed scepticism that she could be open about her intent to introduce a new compliance process for a key stakeholder. She felt that discussing this process with the stakeholder might trigger such strong reactions in the other that the relationship would be destroyed. But the relationship would arguably have been destroyed anyway when the stakeholder learned the process had been introduced without their knowledge. Furthermore, there are ways of framing a conversation to allow even the most difficult topics to be discussed. 


\section{Proof}

For example, continuing this example, the following passage illustrates how a leader might skilfully elicit the stakeholder perspective in this difficult situation:

'The intention of this system is to improve services to clients and public accountability. It seems to me highly likely that this system or something like it will be introduced. It is in my interest to make sure that all the key players are reasonably satisfied with the introduction of this system because your cooperation will be critical to its long-term success. I can see merits in the system and one way we could approach this would be for us to have a debate about it with me presenting my arguments and you presenting yours. But this is unlikely to end in a solution that is mutually acceptable because it is unlikely each of us will be able to set aside our own views enough to fully understand the other's perspective. So I would like to try something different and use this meeting to suspend arguing my perspective for now so that I can fully listen to yours. What I would like for this meeting is, as best I can, to learn to see the issue "through your eyes". So I intend to listen as closely as I can to your perspectives and to check my understanding as I learn more. I would greatly appreciate it if you were to tell me when you think I am not appreciating your perspective as fully as I might. How does that sound to you?'

Assuming the leader is then able to reflectively listen to the stakeholder, they are then in a stronger position to request the same respectful attention to their perspective.

\section{In conclusion}

Faced with the need to demonstrate their ability and establish their authority, tacit models of 'heroic' leaders who have all the answers seduce new leaders into thinking that private processing of information and unilateral action is the way to accomplish these aims. This tendency is further exacerbated by a natural tendency to narrow attention in reaction to stressful situations. Unfortunately, the complex issues faced in most public service agencies are such that private reasoning regarding critical problems is a luxury that can no longer be afforded. If we are to make progress on our most pressing and systemic issues, we are going to have to learn to face the discomfort associated with exposing our reasoning to scrutiny and thereby communicating and collaborating more effectively. The process of succession into a new leadership role is a unique opportunity to develop and demonstrate the possibilities arising from more public and careful reasoning. 


\section{Bibliography}

Alford, J. and Hughes, O. (2008) 'Public value pragmatism as the next phase of public management', American Review of Public Administration, 38(2), 130-48.

Appelbaum, S. H. and Valero, M. (2007) 'The crucial first three months: An analysis of leadership transition traps and successes', Journal of American Academy of Business, 11(1), 1-8.

Argyris, C. E. and Schon, D. (1978) Organizational Learning: A Theory of Action Perspective (Reading, Mass.: Addison-Wesley).

Atkins, P. W. B. (2008) 'Leadership as response not reaction: Wisdom and mindfulness in public sector leadership', in P. .t Hart and J. Uhr (eds) Public Leadership: Perspectives and Practices (Canberra: ANU E Press), pp. 73-82.

Australian Public Service Commission (2004) 'The integrated leadership system'. Accessed at http://www.apsc.gov.au/ils/index.html.

Avolio, B. J. and Gardner, W. L. (2005) 'Authentic leadership development: Getting to the root of positive forms of leadership', Leadership Quarterly, 16(3), 315-38.

Avolio, B. J., Walumbwa, F. O. and Weber, T. J. (2009) 'Leadership: Current theories, research, and future directions', Annual Review of Psychology, 60(1), 421-49.

Bass, B. M. and Steidlmeier, P. (1999) 'Ethics, character, and authentic transformational leadership behavior', Leadership Quarterly, 10(2), 181-217.

Brown, K. W., Ryan, R. M. and Creswell, J. D. (2007) 'Mindfulness: Theoretical foundations and evidence for its salutary effects', Psychological Inquiry, 18(4), 211-37.

Burke, C., Sims, D. E., Lazzara, E. H. and Salas, E. (2007) 'Trust in leadership: A multilevel review and integration', The Leadership Quarterly, 18(6), 606-32.

Chan, A., Hannah, S. and Gardner, W. (2005) 'Veritable authentic leadership: Emergence, functioning, and impacts', in W. Gardner, B. Avolio and F. Walumbwa (eds) Authentic Leadership Theory and Practice: Origins, Effects and Development, Monographs in Leadership and Management, Volume 3 (Boston: Elsevier).

Clapp-Smith, R., Vogelgesang, G. and Avey, J. (2009) 'Authentic leadership and positive psychological capital: The mediating role of trust at the group level of analysis', Journal of Leadership and Organizational Studies, 15(3), 227-40.

Deci, E. L. and Ryan, R. M. (1985) 'The general causality orientations scale: Selfdetermination in personality', Journal of Research in Personality, 19(2), 109-34.

Deci, E. L. and Ryan, R. M. (2008) 'Self-determination theory: A macrotheory of human motivation, development, and health', Canadian Psychology/Psychologie canadienne, 49(3), 182-5.

Dirks, K. T. and Ferrin, D. L. (2002) 'Trust in leadership: Meta-analytic findings and implications for research and practice', Journal of Applied Psychology, 87(4), 611-28.

Dörner, D. (1996) The Logic of Failure: Recognizing and Avoiding Error in Complex Situations (Cambridge, Mass.: Perseus).

Fredrickson, B. L. (2000) 'Why positive emotions matter in organizations: Lessons from the broaden-and-build model', Psychologist-Manager Journal, 4(2), 131-42.

Fry, L. W. (2003) 'Toward a theory of spiritual leadership', Leadership Quarterly, 14, 693-727.

Gardner, W. L., Avolio, B. J., Luthans, F., May, D. R. and Walumbwa, F. (2005) '“Can you see the real me?" A self-based model of authentic leader and follower development', Leadership Quarterly, 16(3), 343-72.

Getha-Taylor, H. (2008) 'Learning indicators and collaborative capacity: Applying action learning principles to the U.S. Department of Homeland Security', Public Administration Quarterly, 32(2), 125-46. 


\section{Proof}

Gilbert, D. T. (1991) 'How mental systems believe', American Psychologist, 46(2), 107-19.

Gillespie, N. A. and Mann, L. (2004) 'Transformational leadership and shared values: The building blocks of trust', Journal of Managerial Psychology, 19(6), 588-607.

Hooijberg, R. and Schneider, M. (2001) 'Behavioral complexity and social intelligence: How executive leaders use stakeholders to form a systems perspective', in S. J. Zaccaro and R. J. Klimoski (eds) The Nature of Organizational Leadership: Understanding the Performance Imperatives Confronting Today's Leaders (San Francisco: The Jossey-Bass business and management series), pp. 104-31.

Hughes, L. (2005) 'Developing transparent relationships through humor in the authentic leader-follower relationship', in W. Gardner, B. Avolio and F. Walumbwa (eds) Authentic Leadership Theory and Practice: Origins, Effects and Development, Monographs in Leadership and Management, Volume 3 (Boston: Elsevier).

Jentz, B. (2008) How to Begin a Leadership Position Successfully: The Entryplan Approach, business edn (Newton, Mass.: Leadership and Learning Inc).

Karp, T. and Helgø, T. I. T. (2008) 'From change management to change leadership: Embracing chaotic change in public service organizations', Journal of Change Management, 8(1), 85-96.

Kegan, R. (1994) In Over Our Heads: The Mental Demands of Modern Life (Cambridge, Mass.: Harvard University Press).

Kernis, M. H. (2003) 'Toward a conceptualisation of optimal self-esteem', Psychological Inquiry, 14, 1-26.

Kouzes, J. and Posner, B. (2006) 'It's not just the leaders vision', in F. Hesselbein and M. Goldsmith (eds) The Leader of the Future 2 (San Francisco: Jossey-Bass), pp. 207-14.

Mazutis, D. and Slawinski, N. (2008) 'Leading organizational learning through authentic dialogue', Management Learning, 39(4), 437-56.

Palanski, M. and Yammarino, F. (2009) 'Integrity and leadership: A multi-level conceptual framework', Leadership Quarterly, 20(3), 405-20.

Popper, M. and Lipshitz, R. (2000) 'Organizational learning: Mechanisms, culture and feasibility', Management Learning, 31(2), 181-96.

Sapolsky, R. M. (1995) Why Zebras Dont Get Ulcers: A Guide to Stress, Stress-Related Diseases, and Coping (New York: W.H. Freeman and Company).

Simons, T. L. (2002) 'Behavioral integrity: The perceived alignment between managers' words and deeds as a research focus', Organization Science, 13, 18-35.

Stone, D. N., Deci, E. L. and Ryan, R. M. (2009) 'Beyond talk: Creating autonomous motivation through self-determination theory', Journal of General Management, 34(3), 75-91.

Tversky, A. and Kahneman, D. (1974) 'Judgment under uncertainty: Heuristics and biases', Science, 185(4157), 1124-31.

Walumbwa, F., Avolio, B., Gardner, W., Wernsing, T. and Peterson, S. (2008) 'Authentic leadership: Development and validation of a theory-based measure', Journal of Management, 34(1), 89-126. 